\title{
ASSESSMENT OF PULVERIZED-COAL-FIRED \\ COMBUSTOR PERFORMANCE
}

DOE/PC/30297--T7

DE82 009955

Fifth Quarterly

Technical Progress Report

for the Period

October 1 - December 31, 1981

W. Richter

W. Clark

R. Payne

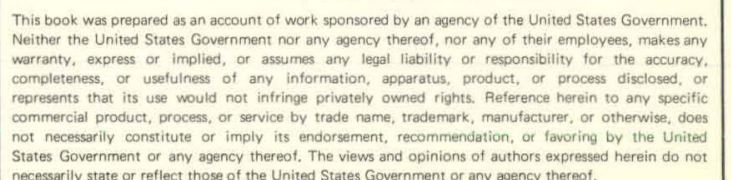

States Government or any agency thereot. The views and opinions of authors expressed herein do not
nof

\section{Energy and Environmental Research Corporation 18 Mason \\ Irvine, CA 92714}

\section{Prepared for Pittsburgh Energy Technology Center Department of Energy}

Under Contract No. DE-AC22-80PC30297 


\section{DISCLAIMER}

This report was prepared as an account of work sponsored by an agency of the United States Government. Neither the United States Government nor any agency Thereof, nor any of their employees, makes any warranty, express or implied, or assumes any legal liability or responsibility for the accuracy, completeness, or usefulness of any information, apparatus, product, or process disclosed, or represents that its use would not infringe privately owned rights. Reference herein to any specific commercial product, process, or service by trade name, trademark, manufacturer, or otherwise does not necessarily constitute or imply its endorsement, recommendation, or favoring by the United States Government or any agency thereof. The views and opinions of authors expressed herein do not necessarily state or reflect those of the United States Government or any agency thereof. 


\section{DISCLAIMER}

Portions of this document may be illegible in electronic image products. Images are produced from the best available original document. 
T.0 INTRODUCTION AND SCOPE

There are substantial economic incentives to explore the possibility of converting boilers and other industrial processes from natural gas or oil to pulverized-fuel firing; however, such a change can have a consịderable impact on the thermal performance of the system, due mainly to:

- Fuel specific adiabatic flame temperatures.

- Different flow and combustion patterns in the furnace.

- Differences in the type and concentration of radiative species, especially particulates, in the combustion products.

- Ash deposition on heat transfer surfaces.

This program is concerned with the provision of a technology base to expedite the conversion of industrial processes from oil and gas to coal and other pulverized fuels. It addresses primarily the impact of fuel type on the thermal performance of a combustor. The program incorporates two experimental tasks and is constructed around an analytical task (Task 1) which will identify and upgrade a family of computer programs required to undertake thermal performance analysis studies. These analytical tools will thus be used to predict the effects of parameters such as fuel type and furnace variables on combustor performance, and to identify those properties which have a major impact on thermal performance. The second task uses a combustion reactor to screen the key variable identified in Task 1 and to provide data on the properties of coal particuiate matter which affect heat transfer performance. Verification of the engineering analytical approach will be provided by measurements made in a pilot-scale furnace in-the third task. 
During the fifth quarterly period of the program, efforts have continued to focus on the analytical tool development and verification. task, and on the bench-scale experimental reactor studies for the screening of key combustion variables.

In previous quarters, the selection, upgrading and verification of the required furnace heat transfer models have been reported. These models are now fully operational and have been used to complete a series of screening studies to identify those parameters which most significantly affect the thermal performance of combustion systems. In this present period, the multizone furnace heat transfer model has been further refined by the deve1opment of a separate but fully coupled submodel for the calculation of char burnout. This aspect of combustor performance is believed to be an important consideration in the conversion of furnaces to coal firing. Char burnout will not only impact the amount of unburned carbon at the stack, but will also affect local heat transfer levels through the extension of heatrelease zones and modification of the properties of the radiating species.

In the experimental portion of the program, efforts have focused on the modification of the reactor feed system and measurement techniques in order to alleviate problems leading to poor data repeatibility. 


\subsection{Task 1--Model Improvement and Engineering Analys is}

During the fifth quarterly research period, efforts of Task 1 were directed towards further work on the multizone furnace heat transfer model and towards the completion of parametric screening studies of thermal performances of combustors. The major part of the upgrading work on the furnace model consisted of the development and testing of a program module for the calculation of char particle burnout and in the coupling of this submodel with the 3D code for the computation of radiative and total furnace heat transfer. Further upgrading work concerned the implementation and testing of an imporved weighted gray gas approach for the computation of real gas radiation within the furnace model. The upgrading work on the burnout model will be described in the following section. Since the results of the parametric screening studies of combustor performance are to be documented in a special report (Ref. 1), the present quarterly report summarizes these studies only (section 3.1.2).

\section{$3.1 .1^{\circ}$ Char Burnout Model}

The multizone heat transfer model chosen as the analytical tool for the assessment of combustor performance is a so-called decoupled model; i.e., it is based on a prescribed flow and heat-release pattern in a furnace. Furthermore, the concentration of species required for the computation of thcrmophysical and radiative properties of the furnace medium is also specified prior to the computation of zonal heat exchange. The decoupling of the momentum and mass balances is mainly carried out in order to reduce the computational effort. A numerical solution of these balances for accurate preductions of individual burner flow and mixing patterns would require a much finer computing grid than the zone arrangement currently used for calculation of radiative and total heat exchange. in the furnace.

The extent of the heat-release zones in gas-and oil-fired furnaces are nearly identical with the shape of the flames obtained by visual inspection; thus, an approximate assessment of the heal release 
distribution within these furnaces is generally possible. Earlier studies for a gas-fired boiler combustion chamber (Ref. 2) have shown that predictions of overall and local heat transfer are quite insensitive with respect to a precise location of the heat-release zones. This is especially true when the flames are small compared to the radiating furnace volume. In this case, it is also justified to assume that the radiating gaseous species, as well as eventual "background" soot (unburnt soot escaping the luminous flame zones), are uniformly distributed throughout the furnace volume. In the case of luminous flames, it is further assumed that the heat release zones are characterized by a larger value of soot concentration. This value is calculated from a simple formation model depending on fuel composition. The validity of the above assumptions has been verified by comparison of predicted and measured heat transfer in a furnace fired alternatively with gaseous and liquid fuels (Ref. 3).

When pulverized coal is fired, an a priori specification of the extent of heat release zones is more difficult. Although there will be, at least for lower rank coals, a more or less visible flame envelope due to the luminosity caused by the burning of coal volatile matter, a certain amount of larger coal char particles will continue to burn outside the luminous flame even if mixing is complete. This amount has been neglected in the past and coal flames have been handled like oil flames with the additional assumption of a uniform distribution of ash particles throughout the furnace volume. The presence of char particles which contribute to the radiative exchange has been restricted to the luminous flame zones. The value for the concentration and specific surface area necessary to calculate the contribution to the overall cloud absorption coefficients of these zones were based on estimates only.

In order to allow an estimation of the amount of unburnt char particles at the exit of p.f.-fired furnaces; a more precise determination of the extent of heat-release zones; and a more reliable assessment of the particle cloud absorption coefficients, the current version of the furnace heat transfer model has been extended to include an optional program module for char burnout. The development was carried out in two stages. The 
first stage included the decoupled computation of burnout of mono- or. polysized particle fractions from temperature distributions obtained in the furnace beat transfer model and a prescribed flow pattern of the particulates. In this simple program option, the oxygen environment is also prescribed. In a more advanced program option, the burnout model is directly coupled to the solution of zonal heat balances in order to evaluate the amount of heat liberated by char combustion at each iteration cycle. Instead of being prescribed, the necessary $\mathrm{O}_{2}$ concentrations are al.so computed from zonal balances; furthermore, the specific surface area of the cloud of char particles is computed for each zone of the furnace, individually. Concentration values and specific surface area are then used for the calculation of the locally varying absorption coefficient of the cloud of char particles at each iteration step. The fundamentals and some results of the char burnout model are.described in the following.

\subsubsection{Computation of Burnout of a Single Char Particle}

\section{Assumptions}

- The particle is spherical.

- It is composed of fixed carbon and inherent ash.

- The (initial) density of the particle is computed from the weight loss due to complete devolatilization according to the proximate analysis of the coal.

- Swelling is neglected.

- The particle burns approximately at constant density; i.e., with decreasing diameter.

- The reaction taking place at the particle surface is

$$
2 \mathrm{C}+\mathrm{O}_{2} \rightarrow 2 \mathrm{CO} \text {. }
$$

- The burning rate is controlled either by the chemical reaction at the surface or by diffusion of oxygen through the boundary layer around the particle.

- There is no relative motion between the particle and the 
surrounding gases; i.e., the Nusselt Number of mass transfer is assumed to be 2 .

- The particle has a uniform temperature.

- This particle temperature equals the temperature of the surrounding gas phase.

Based on the above assumptions, the decrease in mass of carbon of the particle per unit time is expressed as:

$$
\frac{d M_{c}}{d t}=\frac{\pi x^{2}}{\sqrt[1]{\frac{4 \pi{ }_{C} D_{2}-N_{2}}{x R^{* T}}+1 / A \exp (-E / R T)}} P_{0_{2}} .
$$

The density of the char particle is calculated from

$$
\rho_{c}=\left(m_{c, f i x}+m_{a s h}\right) \rho_{c o a l} \text {. }
$$

$m_{c, f i x}$ and $m_{a s h}$ are the fixed carbon and ash content determined from the proximate analysis. $\rho_{\text {coal }}$ is the apparent density of the parent coal. A value of $\rho_{\text {coal }}=1300 \mathrm{~kg} / \mathrm{m}^{3}$ is suitable for low-ash coals. The diffusion of oxygen through the boundary layer of the particle is expressed as binary $\mathrm{O}_{2}-\mathrm{N}_{2}$ diffusion. The corresponding diffusion coefficient $\mathrm{O}_{2}-\mathrm{N}_{2}$ is com-
puted from:

$$
\mathrm{V}_{\mathrm{O}_{2}-\mathrm{N}_{2}}=\mathrm{D}_{0}\left(\frac{\mathrm{T}}{\mathrm{T}_{0}}\right)^{1.75}
$$

with $D_{0}=34910^{-6} \mathrm{~m}^{2} / \mathrm{s}$ and $T_{0}=i 600^{\circ} \mathrm{K}$. Suitable values for the frequency factor $A$ and the activation energy $E$ depend very much on the coal type. The following set of values have been alternatively used:

$$
\begin{array}{lll}
A=85961 & A=693.8 & \frac{\mathrm{kg}}{\mathrm{m}^{2} \mathrm{~s} \text { bar } 0_{2}} \\
E=149469 & E=89890.6 & \frac{\mathrm{kJ}}{\mathrm{kmole}}
\end{array}
$$

The first set is recommended in Ref. 4 as an average value for coals with the exception of anthracites. The second set taken from Ref. 5 represents 
a lower limit of the chemical reaction rate for nonswelling bituminous coals and an upper limit for swelling bituminous coals.

In order to evaluate the progress of burnout of a single particle with eq. (1), depending on its position in the furnace, the particle trajectory and the velocity and oxygen concentration along this trajectory must be known. The temperature distribution along the particie path is supplied by the furnace heat transfer model. The assessment of particle trajectories and velocities is easy in furnaces with plug flow. Difficulties are, however, encountered in furnaces with recirculating flow patterns, since particles at the same position in the furnace will have different sizes; i.e., a particle found at the furnace exit might have followed different trajectories. A mean value of burnout of monosized particles in the furnace with recirculating flow is obtained by the following model.

\subsubsection{Burnout of a Monosized Particle Cloud in a 3D Furnace}

\section{Assumptions}

- Particles follow the mean flow pattern used for the heat transfer calculations with the multi-zone model.

- A uniform weight mean diameter is assigned to all particles leaving a (well-stirred) furnace zone.

- Diffusion of particles is neglected.

- Devolatilization is accomplished in the zone immediately following burner inlets.

- Oxygen concentration in the heat release zone corresponds to complete burnout of the volatile matter, oxygen concentration outside the heat-release zone corresponds to complete burnout of total combustibles.

With assumption (1) the mass balance of a monosized fraction of char particles in a furnace zone I reads:

$$
\dot{M}_{c, c, I}+\dot{M}_{c, c h, l}=0 \text {. }
$$


$\dot{M}_{c, c, I}$ is the net convective flow of char particles into a volume zone $I$. It is expressed in analogy to the total heat balance presented for a 3D arrangement of volume zones in Ref. 6 (eq. 32):

$$
\begin{aligned}
\dot{M}_{c, c, I}= & \dot{M}^{+}{ }_{i-1 / 2, J, k} \cdot m_{c, 1-1, j, k}+\ldots+\dot{M}_{i+1 / 2, j, k} \cdot m_{c, i+1, j, k} \ldots \\
& -\left(\dot{M}^{+}{ }_{i-1 / 2, j, k}+\ldots . . \dot{M}_{i+1 / 2, j, k}^{-}+\ldots\right) m_{c, i, j, k} \cdot \quad \text { (4) }
\end{aligned}
$$

$m_{c}$ is the mass concentration of char particles. $\dot{M}^{+}$and $\dot{M}^{-}$are the total mass flow rates over the zone boundaries in positive and negative directions, respectively.

$\dot{M}_{c, c h, I}$ is the decrease of mass of carbon in the zone I per unit time due to combustion of the char particles. This quantity is evaluated similar to eq. (1) for burnout of a single particle:

$$
\dot{\bar{M}}_{c, c h, I}=\frac{6}{\rho_{p} \bar{x}} \frac{1}{1 \frac{4 m_{c} D_{O_{2}-N_{2}}+1}{\bar{x} R^{*} T} \exp (-E / R T)} \Delta V \rho_{m} \cdot m_{c}
$$

Each variable quantity in this source term corresponds to zone I (i.e., the indices $i, J, k$ have been omitted). $\Delta V$ is the volume of this zone and $\rho_{m}$ is the density of the furnace medium. Taking assumptions (1) and (2) into account, the weight mean diameter of the particle cloud in the zone $I$ is computed from

$$
\bar{x}=x_{0}^{3}\left(m_{c} /\left(m_{c}\right)_{0}\right)^{1 / 3} \text {. }
$$

$m_{c} O$ is the mass concentration of char particles at one burner inlet or the uniform value of char concentration at all burner inlets, and $x_{0}$ is the corresponding initial diameter of the monosized particle fraction. Based on the flow and temperature data from the heat transfer model, the balance equation (3) is solved iteratively for the unknown zonal char. concentration $\mathrm{m}_{\mathrm{c}}$, I with a combined Gauss-Seidel and Newton Raphson solution technique:

$$
m_{c, I, n}=m_{c, I, n-1}-\frac{\dot{M}_{c, c, I}+\dot{M}_{c, c h, I}}{\left[\frac{\partial}{\partial_{m_{c}}}\left(\dot{M}_{c, c, I}+\dot{M}_{c, c h, I}\right)\right]_{n-1}} \text {. }
$$


The burnout model for monosized particle fractions has been applied to calculate unburnt char at the exit of a tangentially fired coal combustion chamber of 875 MW fuel heat input. The coal was a medium bituminous coal, and reaction rate constants used were those recommended in Ref. 4. Since the char concentration shows a profile even at the furnace exit, the values of unburnt carbon listed in Table 1 represent mass flow averaged values at this cross-section.

Table 1. Percentage of Unburnt Carbon Evaluated for Different Particle Sizes at the Exit of a Tangentially Fired $875 \mathrm{MW}_{\text {th }}$ Cóal Combustion Chamber

\begin{tabular}{|c|c|c|}
\hline & $\begin{array}{c}\text { Size Fraction } \\
10^{-6} \mathrm{~m}\end{array}$ & $\begin{array}{c}\text { Unburnt Carbon } \\
\%\end{array}$ \\
\hline \hline$\varepsilon_{\mathrm{w}}=0.9$ & 50 & 0.00 \\
& 100 & 0.05 \\
& 200 & 21.88 \\
\hline$\varepsilon_{\mathrm{w}}=0.6$ & 150 & 4.37 \\
& 200 & 19.54 \\
\hline
\end{tabular}

It can be seen that particles with sizes larger than $200 \mu m$ are difficult to burn, even in large p.f. combustion chambers. Burnout is moderately improved when the furnace walls have a lower emissivity; since, in this case, a higher overall temperature level was predicted for the furnace.

\subsubsection{Model of Burnout of Polysized Char Particles}

The model of burnout of a monosize particle fraction was "extended to handle the burnout of complete particle distributions with up to ten monosized fractions. This is done by applying the above model successively 
for the various size fractions and by accumulating the unburnt in the fractions for each volume: zone I according to:

$$
U_{I}=\frac{\sum_{l=1}^{n} m_{c, l, I}}{\left(m_{c}\right)_{0}},
$$

where $\left(m_{c}\right)_{0}$ is the total char concentration at the inlet of each burner. $m_{c, 0}$ itself calculated from

$$
m_{c, 0}=\sum_{l=1}^{n}\left(m_{c, l}\right)_{0} .
$$

The approximation of the initial polysized particle distribution by monosized fractions is carried out in such a way that each fraction has nearly the same specific surface area. The following scheme is applied for determining the initial lower, upper, and mean diameter of each size class:

$$
\begin{aligned}
& x_{\ell-1 / 2}=(1-\delta) x_{\ell}, \\
& x_{\ell+1 / 2}=(1+\delta) x_{\ell} \\
& x_{\ell}=\left(x_{\ell-1 / 2}+x_{\ell+1 / 2}\right) / 2 .
\end{aligned}
$$

Provided the smallest diameter $x_{-1 / 2}$ and the largest diameter $x_{n+1 / 2}$ of the distribution are known, the size increment $\delta$ is computed from

$$
\delta=\frac{\left(\frac{x_{n+1 / 2}}{x-1 / 2}\right)^{\frac{1}{n}}-1}{\left(\frac{x_{n+1 / 2}}{x-1 / 2}\right)^{\frac{1}{n}}+1}
$$

The diameters $x_{\ell-1 / 2}$ and $x_{\ell+1 / 2}$ evaluated with the above scheme are used to determine the ratio $\left(m_{c, l}\right)_{0} /\left(m_{c}\right)_{0}$ from the given size distribution.

\subsubsection{Direct Coupling of the Burnout Model for Polysized Char Particles With the Heat Transfer Furnace Model}

During the computation of burnout in a large tangentially fired boiler with the above model, it was observed that the coarser fractions of a given size distribution caused a large amount of unburnt carbon at the 
furnace exit plane. Since it was believed that this amount of unburnt carbon would also have an impact on the heat release pattern and consequently on heat flux and temperature distributions in the furnace, the burnout model was directly coupled with the furnace heat transfer model. The following additional assumptions were necessary:

\section{Assumptions}

- Complete mixing of fuel and air at the burner inlets.

- $\quad \hat{A}$ priori specification of the extent and distribution of heat release due to burning of volatiles.

- Infinitely fast burning of char gasification product $C O$ outside the particle boundary layer.

The distribution of $\mathrm{O}_{2}$ in the furnace is either prescribed or, optionally, computed from the following balance:

$$
\dot{\mathrm{M}}_{\mathrm{O}_{2}, \mathrm{c}, \mathrm{I}}+\dot{\mathrm{M}}_{\mathrm{O}_{2}, \mathrm{ch}, \mathrm{I}}=0
$$

$\dot{\mathrm{M}}_{\mathrm{O}_{2}, \mathrm{c}, \mathrm{I}}$, the convective transport into a zone $\mathrm{I}$, is expressed in similar manner to eq. (4). The source term $\dot{\mathrm{M}}_{\mathrm{O}_{2}, \mathrm{ch}, \mathrm{I}}$ consists of two parts describing the consumption by combustion of volatiles and char, respectively:

$$
\dot{\mathrm{M}}_{\mathrm{O}_{2}, \mathrm{ch}, \mathrm{I}}=\dot{\mathrm{M}}_{\mathrm{O}_{2}, \mathrm{vol}, \mathrm{I}}+\mathrm{v} \sum_{\ell=1}^{n} \dot{\mathrm{M}}_{\mathrm{c}, \mathrm{ch}, \ell, \mathrm{I}},
$$

where $v$ is the stoichiometric coefficient of the $\mathrm{C}-\mathrm{O}_{2}$ reaction with end product $\mathrm{CO}_{2}$. For the actual solution of the $\mathrm{O}_{2}$ balance, the balance equations for the various char fractions and eq. (13) are combined to eliminate the source term due to char combustion. Thus, the $\mathrm{O}_{2}$ concentration $\mathrm{m}_{2}$ is. replaced by a new variable

$$
\sum_{\ell=1}^{n} m_{c, l}-\frac{m_{0}}{v} \text {. }
$$

The balance equation for this quantity. is simultaneously solved with the equations for the char fractions following the same numerical solution scheme (see eq. 7). 
The direct coupling of the burnout model to the total heat balance is carried out in the following way:

During each cycle of iteration of total heat balance, $C$ and $\mathrm{O}_{2}$ balances are subiterated. The number of subiterations is arbitrary; current calculations were carried out with 5 subiterations per cycle. The number of main iterations to achieve convergence of total heat balance was 60 for an investigated arrangement of $55^{\star} 15$ zones.

After each cycle of subiterations, the gray absorption coefficient of the char particle cloud of each zone is updated according to equation (14):

$$
k_{c}=x_{a} \frac{3}{2 \rho_{c}} \rho_{m} \sum_{\ell=1}^{n} \frac{m_{c, l}}{x_{\ell}} .
$$

The coupled burnout and heat transfer model was applied to several furnace configurations. Figure 1 shows an example for a tangentially coal-fired furnace where the predicted distributions of unburnt carbon, $\mathrm{O}_{2}$-concentration and specific surface area of char particles along a representative column of furnace volume zones are presented. The computations shown in this figure were carried out for 80 percent and 50 percent thermal load, and the reaction rates used were those cited earlier from ref. 5. The initial size distribution of the coal particles investigated was very coarse; i.e., the weight mean diameter $\bar{x}$ was about $90 \mu \mathrm{m}$. This explains the relatively high amount of unburnt carbon of the furnace exit. It can be clearly seen that unburnt carbon is reduced at partial load. This is due to an increase in residence time which exceeds the effect of delayed burnout due to a decrease of temperature level in the furnace at partial load. The specific surface area of the char particles decreases with progress of burnout and is completely dominated by the delayed burnout of the larger particles towards the furnace exit.

\subsubsection{Parametric Screening Studies for the Calculation of-Heat Transfer in Combustion Chambers}

During the reported research period, parametric screening studies were conducted in order to identify those parameters most influencing the thermal performance of full-scale combustion chambers, such as industrial 


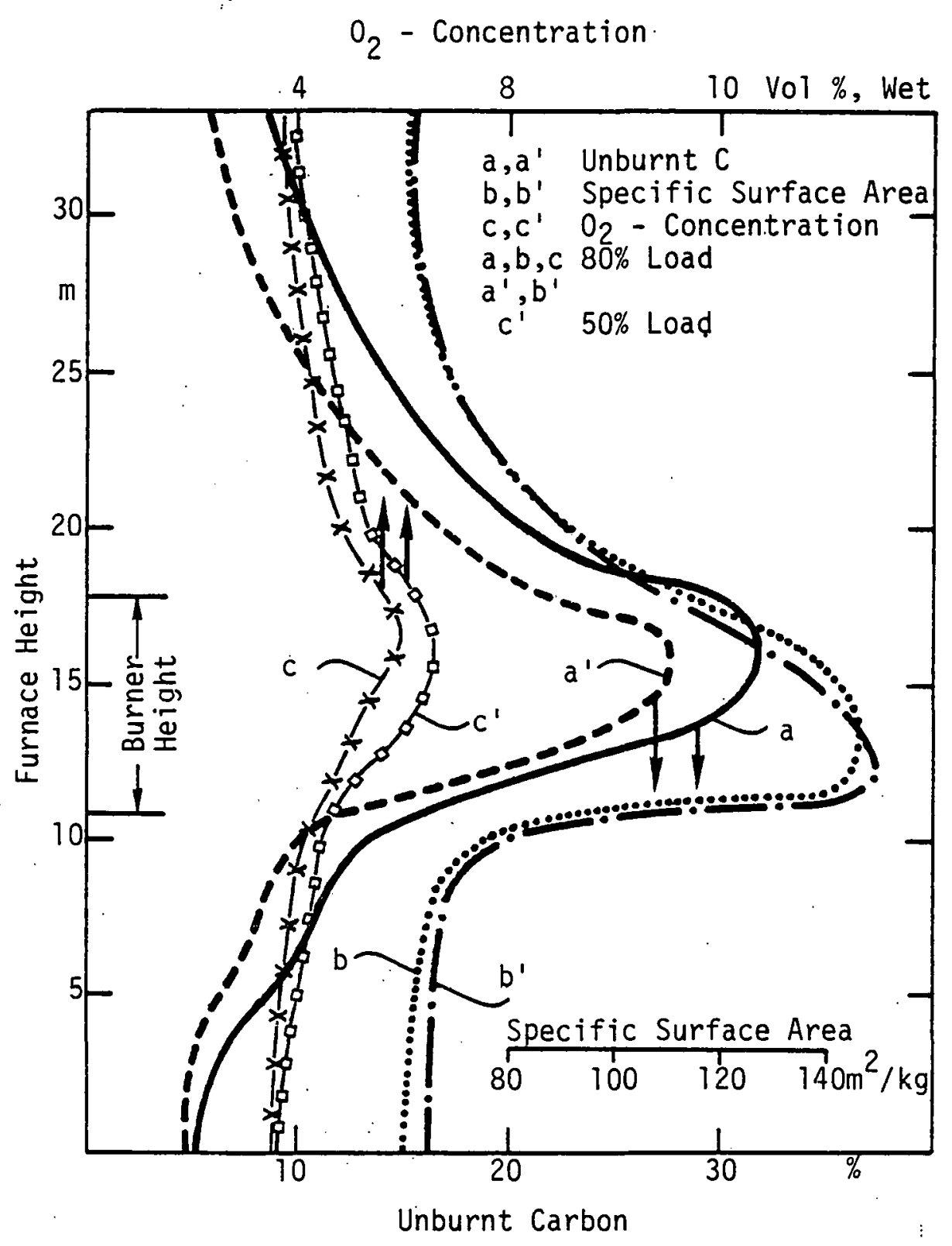

Figure 1. Unburnt Carbon, Specific Surface Area and $\mathrm{Q}_{2}$-Concentration at Different Loads for a Representative. Column of Volume Zones of a Tangentially Fired Coal Combustion Chamber With Coarse Size Distribution of Char Particles $(\bar{x} \quad 90 \mu \mathrm{m})$. 
furnaces or utility boilers. Special attention has been given to pulverized coal firing and a detailed report on these studies will shortly be completed. (Ref. 12. In the following discussion, the content of this report are summarized. In the report, the parametric screening studies will be described in two parts. Part I deals with overall thermal behavior of furnaces expressed in terms of a furnace efficiency and a furnace exit temperature. In Part II, local heat transfer characterized by local temperature and heat flux distributions is investigated and the impact of local inhomogeneities of furnace variables on thermal performance shown.

The screening studies concerning the overall thermal behavior have been carried out by means of a well-stirred analysis of the furnace. The following quantities were identified as important parameters for overall furnace heat absorption:

- (Pseudo) Adiabatic Flame Temperature

- Firing Density

- Emissivity of Furnace Volume for $\varepsilon_{f}<0.3$

- Temperature of Heat Sink Walls for $T_{w}>700^{\circ} \mathrm{K}$

- Emissivity of Heat Sink Walls for $\varepsilon_{f}>0.3$

The furnace efficiency has also been linked to the dimensions of the furnace volume. The most striking feature found was that the thermal performance of large combustive chambers; and, consequentily the furnace height required for prescribed furnace exit temperature, is very sensitive to the temperature of the heat sink walls if these are larger than $700^{\circ} \mathrm{K}$. For instance, in order to maintain the same exit temperature $T_{\text {ex }}=1440^{\circ} \mathrm{K}$ of a $500 \mathrm{MW}_{\text {th }}$ furnace obtained for $T_{W}=700^{\circ} \mathrm{K}$ at a surface temperature $T_{W}=1300^{\circ} \mathrm{K}$ (which can easily be reached by heat sink deposit layers), it is necessary to increase the furnace height by more than 50 percent of the original height corresponding to clean walls.

As a supplement to the well-stirred analysis of a furnace the effect of the different radiative species (gas, soot, char, and ash) on the furnace emissivity has been quantified by means of simple approaches. The emissivity data and adequate estimations of concentration levels were 
used together with the well-stirred analysis to demonstrate the relative importance of the different radiating species on overall furnace heat transfer. Investigated also was the sensitivity of the predictions with respect to uncertainties in the determination of either optical properties or concentrations of radiating species. The following was found: With the exception of furnaces fired with gas as high-ash coals, the uncertainty in soot concentration and emissivity is the major source of error in the prediction of total heat absorption. In furnaces fired with gas and low-ash coal as well as in larger oil-fired furnaces, the uncertainty in the approximation of gas emissivity plays also a significant role for accurate predictions of $\eta_{f}$. Considerable inaccuracies in total heat transfer predictions can be caused by uncertain radiative properties of ash particles even for a coal with low ash content. In furnaces. fired with high-ash coal, reliable model ing of radiation from ash particle clouds is crucial.

The second part of the screening. studies, which was carried out with the developed multizone furnace model, shows the impact of flow pattern, local heat release and luminous flame zones on temperature and heat flux profiles as well as on overall thermal performance for an idealized boiler combustion chamber. It was found that a change of the recirculation pattern in the furnace bottom had only a moderate influence on the heat flux and temperature profiles and on furnace efficiency. Local and overal1. performances for gas and oil firing were also compared. Peak temperatures in the heat-release zone of the coal-fired boiler were $140^{\circ} \mathrm{K}$ lower than for methane firing and predicted peak fluxes for coal firing were twice as high as those predicted for gas firing. This corresponds to an increase in furnace efficiency of almost 10 percentage points. The increase of furnace heat absorption could be attributed to the strong lacal increase of emissivity due to the presence of char and soot particles in the flame zone. An additional comparison of thermal hehavior of the furnace for five different coals. revealed, except for a lignite, a considerable increase in furnace efficiency with ash content of the coal. The low furnace efficiency of the lignite arises from the very low adiabatic flame temperature due to the high moisture content of this coal. Different excess air had also a strong influence on overall thermal performances and played a considerable role in determining 
maximum temperatures and heat fluxes. The influence of ash deposits on furnace heat transfer of a coal-fired boiler was investigated in a final study (see also Ref, 72. As expected from the foregoing well-stirred analysis, a thin ash deposit layer $\left(\Delta S=0.5 \mathrm{~mm}, \varepsilon_{\mathrm{w}}=0.6\right)$ on the heat sink surfaces was sufficient to reduce considerably furnace heat transfer compared to clean walls and led to a marked redistribution of the heat flux profiles. 
Efforts in the fifth quarter have concentrated on modification of the feed system and measurement techniques in preparation for the detailed measurements.

\subsubsection{Feed System}

Fluctuating coal feed rates have led to inconsistencies in extinction measurements due to changing particle concentrations and combustion conditions. Three improvements have been made to the feed system, shown in Figure 2, to eliminate these fluctuations:

- Narrow size ranges of air-classified coal have been purchased.

- A metallic fluidized bed particle feeder has been fabricated.

- The burner has been simplified to a single injector.

It is difficult to maintain a steady flow of particles containing a wide size distribution from a laboratory-scale fluidized-bed feeder. Oversize particles tend to plug the narrow offtake tube and fine particles tend to agglomerate, upsetting fluidization and clogging the offtake tube or transport system. Sieving and elutriation to eliminate the coarse and most of the fine particles have reduced feeder clogging, but feed rate and particle size have slowly changed with time due to size segregation in the fluidized bed. To avoid clogging and segregation problems the two coals chosen for the detailed measurements, Utah and Four Corners, have been air classified to the following narrow size ranges:

- 90 to 70 micron

- 70 to 50 micron

- 50 to 30 micron

The size distribution of fly ash particles is expected to vary with the size distribution of coal particles according to the model of Flagan (19.79); Ref. 8); thus; combustion of different size cuts of the same coal under similar conditions should give an indication of the effect of particle size on fiy ash extinction efficiency. 


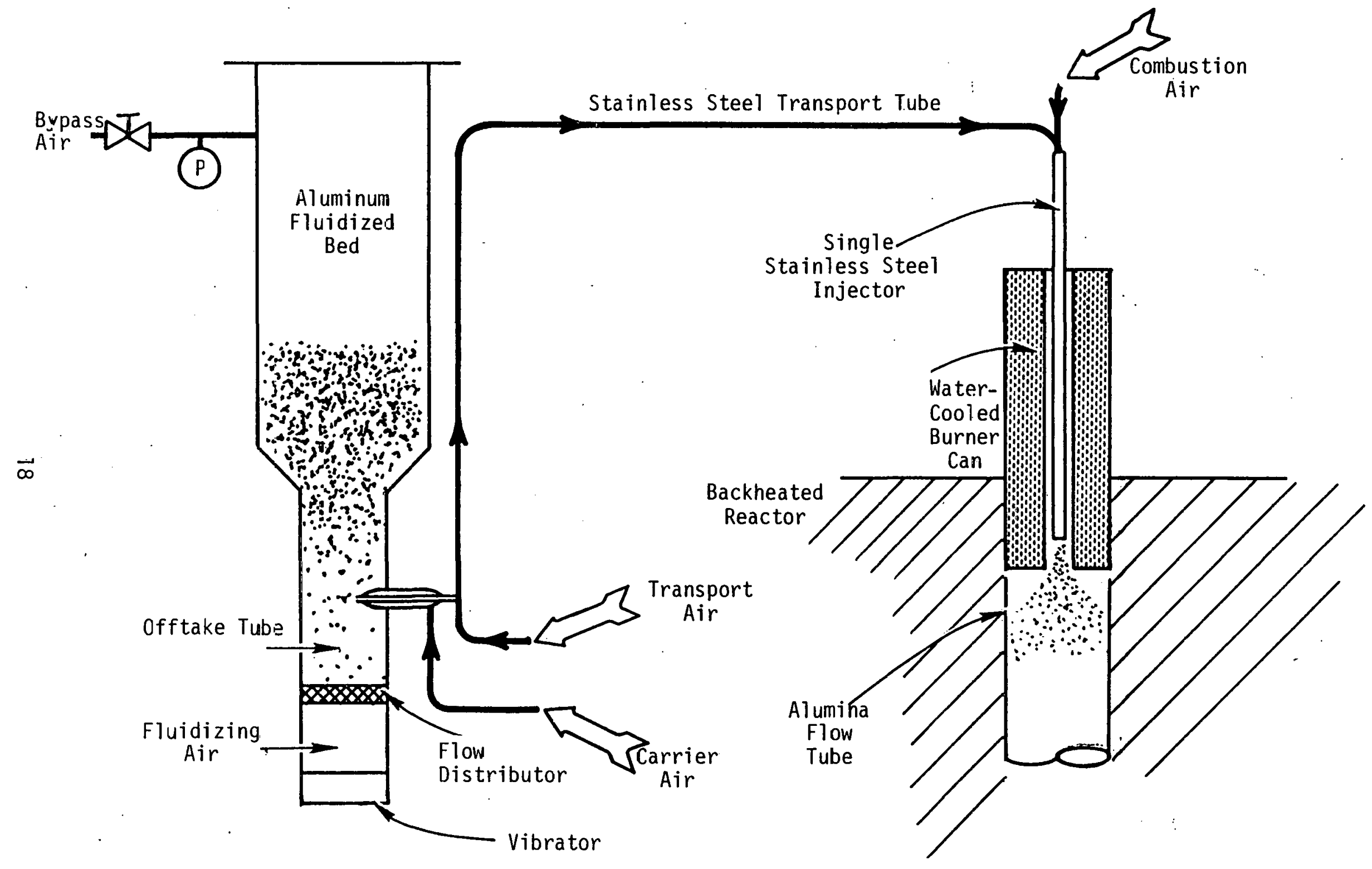

Figure 2. Feed System. 
The continuous movement of particles in a fluidized bed tends to generate static charges which lead to particle agglomeration and accumulation on the walls of the transport tube. The plexiglass fluidized bed has been replaced with a.larger aluminum one which should eliminate static buildup and allow longer periods of continuous operation.

Problems have been encountered in the multiple injector burner system due to particle accumulation in the stream splitter and transport and injector tubes. This buildup has resulted in imbatanced flows and occasional dumping through the injector tubes. The system has been simplified to a single premixed injector, eliminating the splitter and the multiple transport tubes. Visual comparisons of coal flames from the single-injector and multiple-injector burners indicate that the single-injector flame disperses more quickly to evenly fill the flow tube and seldom dumps accumulated particles as does its multiple injector counterpart.

\subsubsection{Measurement Sys tems}

Several improvements have been implemented in the measurement systems to allow more accurate determination of particle extinction coefficient and of combustion conditions. The following systems are discussed:

- Particle sizing

- Radiometer

- Two-color pyrometer

The technique for measuring particle size has been simplified to allow more extensive sampling. It was originally planned to measure particle size distribution over a very wide range using a variety of techniques, each. with different sampling and analysis requirements. The cascade impactor has been chosen as the device with the most appropriate range for measurement of optical area, the parameter of interest for radiation absorption. The Andersen impactor has size cuts over an aerodynamic range of 0.4 to 10 . microns. For spherical particles having a typical ash density of $2.5 \mathrm{~g} / \mathrm{cm}^{3}$, this corresponds to an actual diameter range of 0.24 to 6.1 microns. The optical area peak for most flyashes falls within this range; however, the impactor can be operated at different flow rates to extend the size range. 
The impactor data will be fit to a Rosin-Rammler distribution described by Field et al. (1967), a useful format for further data reduction.

The radiometer system, shown in Figure 3, has been improved to decrease the impact of noise and the measurement technique has been simplified. A preamplifier has been included which applies a gain of 300 . to 3000 to the signal from the pyroelectric detector prior to the frequency-modulated amplifier. Noise-to-signal ratios on the order of 0.5 percent have been measured for unfiltered radiation emitted from the blackbody source through the reactor system. When a 3.6-micron, narrow-pass filter was utilized, the noise increased to about 1 percent of the signal. The light chopper, formerly located between the reactor and the detector, has been moved to a point between the blackbody source and the detector, eliminating one of the Schmidt-method measurements which must be taken for calculation of extinction efficiency. Extinction efficiency is calculated as one minus the ratio of the chopped source signal measured through the particulate cloud to the chopped source signal measured through the particulate cloud to the chopped source signal measured through air.

Two-color pyrometry measurements have been used to estimate particulate temperatures within the combustion zone and in the access module where extinction measurements are taken. The two-color pyrometer probe is aligned to provide an axial view of the entire combustion zone against the cold burner-face background. As radiation intensity increases with temperature, the two-color temperature measured in this fashion is weighted toward the higher values. Two-color measurements have also been taken through the radiometer probe, providing a measure of particle temperatures at the point where extinction measurements are taken. In fuel-lean combustion of Four Corners coal at wall temperatures of $1350^{\circ} \mathrm{C}$, combustion zone particle temperatures around $1700^{\circ} \mathrm{C}$ and access-zone particle temperatures around $1100^{\circ} \mathrm{C}$ have been measured.

\subsubsection{Plans}

During the next quarter it is planned to proceed with the detailed measurements on size-classified Utah and Four Corners coals, investigating effects of coal type and particle size on extinction efficiency. Measured extinction efficiencies will be compared with calculated ones based on measured size distributions and assumed refractive indices. 


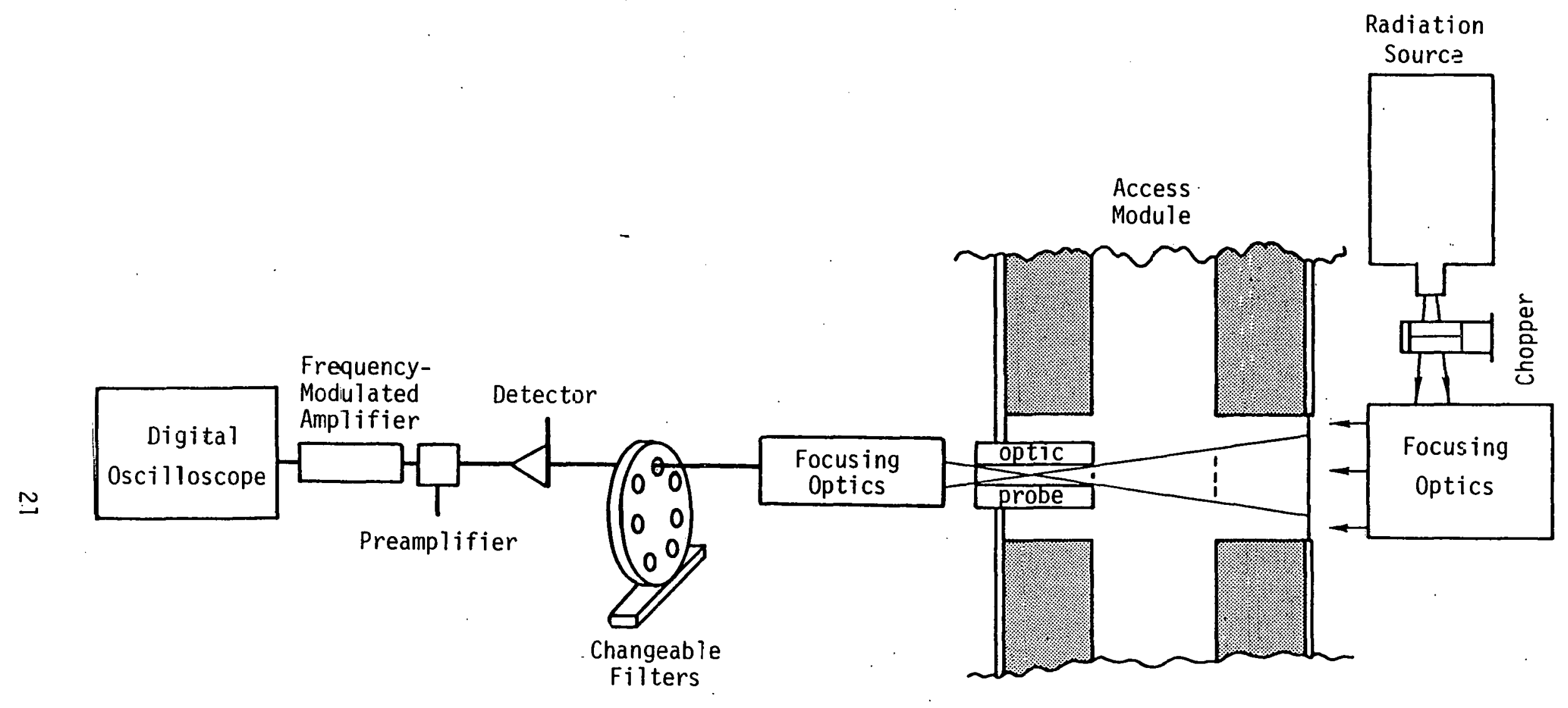

Figure 3. Radiometer System. 


\subsection{REFERENCES}

1. Richter, $W$. Parametric Screening Studies for the Calculation of Heat Transfer in Combustion Chambers. Topical Report. Prepared for Pittsburgh Energy Technology Center, Department of Energy Under Contract No. DE-AC22-80PC30297. January 1.982.

2. Richter, W.; Clark, W.; Payne, R. Assessment of Pulverized-CoalFired Combustor Performance. Contract No. DE-AC22-80PC30297. Third Quarterly Technical Progress Report. July 1981.

3. Richter, W. and Heap, M. P. "Einfluss der Brennstoffart auf die Waermeuebertragung in Feuerungen." VDI-Berichte $\mathrm{Nr} .423 .1981$.

4. Field, M. A.; Gill, D. W. ; Morgan, B. B.; and Hawksley, P. G. W. Combustion of Pulverised Coal. Leatherhead, Surrey, England: The British Coal Utilisation Research Association. 1967.

5. Smith, I. W. The Combustion Rates of Pulverized Coal Char Particles. Paper to "Conference on Coal Combustion Technology and Emission Contro1." Pasadena, February 5-7, 1979. Private Communication. CSIRO, P.0. Box 136, North Ryde, N.S.W. Australia 2113.

6. Richter, W. Models for Coal Combustor Performance. Analytical Tool Verification. Topical Report. Prepared for Pittsburgh Energy Technology. Center, Department of Energy Under Contract No. DE-AC22-80PC 30298. February 1981.

7. Richter, W.; Calrk, W.; and Payne, R. Assessment of PuvlerizedCoal-Fired Combustor Performance. Contract No. DE-AC22-80PC30297. Fourth Quarterly Technical Progress Report. November 1981.

8. Flagan, R. C. Submicron Particles from Coal Combustion, Seventeenth Symposium (International) on Combustion. The Combustion Institute, 1979. 